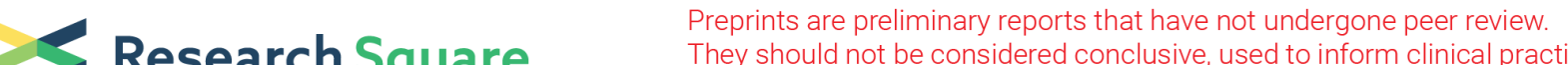 Research Square $\quad \begin{aligned} & \text { They should not be considered conclusive, used to inform clinical practice, } \\ & \text { or referenced by the media as validated information. }\end{aligned}$
}

\section{Trends in Surface Elevation and Accretion in a Retrograding Delta in Coastal Mississippi, USA from $2012-2016$}

Jonathan Pitchford ( $\sim$ jonathan.pitchford@dmr.ms.gov )

Grand Bay National Estuarine Research Reserve https://orcid.org/0000-0003-1168-5087

Kimberly Cressman

Grand Bay National Estuarine Research Reserve

Julia A Cherry

University of Alabama

Brook T Russell

Clemson University

Jay Mcllwain

Grand Bay National Estuarine Research Reserve

Michael J Archer

Grand Bay National Estuarine Research Reserve

William V Underwood

Alabama Department of Conservation and Natural Resources

\section{Research Article}

Keywords: salt marsh, surface elevation table, accretion, sea level rise

Posted Date: January 12th, 2022

DOI: https://doi.org/10.21203/rs.3.rs-1247565/v1

License: (c) (1) This work is licensed under a Creative Commons Attribution 4.0 International License.

Read Full License 
Trends in surface elevation and accretion in a retrograding delta in coastal Mississippi, USA from 2012 - 2016

Jonathan L. Pitchford ${ }^{1}$, Kimberly Cressman ${ }^{1}$, Julia A. Cherry ${ }^{2}$, Brook T. Russell ${ }^{3}$, Jay McIlwain ${ }^{1}$, Michael J. Archer $^{1}$, and William V. Underwood ${ }^{4}$

${ }^{1}$ Grand Bay National Estuarine Research Reserve, Moss Point, Mississippi, USA

${ }^{2}$ University of Alabama, New College, Tuscaloosa, Alabama, USA

${ }^{3}$ Clemson University, School of Mathematical and Statistical Sciences, Clemson, South Carolina, USA

${ }^{4}$ Alabama Department of Conservation and Natural Resources, State Lands Coastal Section, Spanish Fort, Alabama, USA

Corresponding author email: jonathan.pitchford@dmr.ms.gov

Abstract

The Grand Bay estuary is in the north-central Gulf of Mexico and lacks riverine sediment input for marsh elevation maintenance. This study quantified trends in surface elevation change and accretion along an elevation

17 gradient within the estuary. Elevation change rates were compared to short (13.71 mm/yr; 95\% CI: $-2.38-29.81)$, medium (6.97 mm/yr; 95\% CI: 3.31 - 10.64), and long-range (3.50 mm/yr; 95\% CI: 2.88 - 4.11) water level rise (WLR) rates for the region. Elevation change rates ranged from $0.54 \mathrm{~mm} / \mathrm{yr}(95 \% \mathrm{CI}$ : $-0.63-1.72)$ to $5.45 \mathrm{~mm} / \mathrm{yr}$ (95\% CI: 4.27 - 6.62) and accretion rates ranged from $0.82 \mathrm{~mm} / \mathrm{yr}$ (95\% CI: $-0.16-1.80)$ to $3.89 \mathrm{~mm} / \mathrm{yr}$ (95\% CI:

$212.90-4.89)$ among marsh zones. Only the elevation change rate at a Juncus roemerianus marsh located high in the 22 tidal frame was lower than long- $(P<0.001)$ and medium-range WLR rates $(P<0.01)$. The elevation change rate at a

23 lower elevation J. roemerianus marsh was higher than the long-range WLR rate $(P<0.05)$. No marsh zones had

24 elevation change rates that were significantly different from short-range WLR. These results suggest that $J$.

25 roemerianus marshes higher in the tidal frame with limited sediment delivery are the most vulnerable to increases in

26 sea level. Lower elevation marshes had higher rates of elevation change driven by sediment accretion and biogenic

27 inputs. Other local research suggests that shoreline erosion is a threat to marsh persistence but provides elevation

28 capital to interior marshes. Marsh migration is potential solution for marsh persistence in this relatively undeveloped 29 area of the Gulf Coast.

30 Key words: salt marsh, surface elevation table, accretion, sea level rise

33 The authors would like to thank Lindsay Spurrier, Cher Griffin, and Daniel Taylor for assistance with data collection and curation. 
Coastal marshes are complex ecosystems that provide a wide range of valued ecological functions, but they

37 are also subjected to a variety of stressors that could impact their persistence in the landscape. Anthropogenic development is a prominent threat, but sea level rise (SLR) is being increasingly discussed as an additive threat to marshes that has the potential to affect marsh function (Cahoon et al. 2018; Osland et al. 2017). Development and SLR have additive impacts on marshes through "coastal squeeze," where anthropogenic barriers (e.g., roads, residential development, etc.) limit upslope movement of marshes as sea level rises (Borchert et al. 2018). The most obvious impact of coastal squeeze in heavily developed areas would be reductions of marsh extent and the degradation or loss of the ecological functions they provide. In the absence of transgression upslope, marshes must gain elevation at a rate equal to or greater than relative SLR to maintain their current footprint in the landscape. Marsh elevation maintenance relies on sediment or biogenic accretion through biofeedback mechanisms often associated with marsh vegetation (e.g., sediment trapping by stems, root production) (Cahoon et al. 2006,

47 2021). Trends in surface elevation and accretion differ geographically, with the relative importance of physical and biological contributions to elevation maintenance varying within and among different wetland types. For example, in Atlantic coast estuaries, marshes have been shown to have high rates of surface accretion suggesting resilience to increasing sea level, whereas subsurface processes were drivers of elevation maintenance in forested wetlands (Stagg et al. 2016). In other areas along the Atlantic coast, variation in surface elevation change has been noted where local variability in elevation change among habitat types within an estuary was higher than seasonal or longterm variability (Childers et al. 1993). In the Chesapeake Bay, elevation change rates across an elevation gradient ranged from $-9.8 \pm 6.9 \mathrm{~mm} / \mathrm{yr}$ to $4.5 \pm 4.3 \mathrm{~mm} / \mathrm{yr}$ from high to low marsh habitats, suggesting that marsh loss was imminent in some areas, but other areas appeared to be stable (Beckett et al. 2016).

57 loss reported for some areas. For example, several Louisiana marshes are experiencing decreases in elevation from subsidence. Byrnes et al. (2019) documented subsidence rates of $2-7 \mathrm{~mm} / \mathrm{yr}$ within the Barataria Basin, while Lane

59 et al. (2006) measured subsidence rates that ranged from $5.9-27.8 \mathrm{~mm} / \mathrm{yr}$ in estuaries receiving inputs from

60 freshwater diversions. In St. Joseph Bay, Florida, marsh elevation was decreasing, while in Apalachicola Bay,

61 Florida marsh elevation was increasing in some areas, decreasing in others, and in some cases no trend was detected 62 (Program for Local Adaptation to Climate Effects 2021). Elevation change rates differed with wetland type in Ten 
Thousand Islands, Florida with salt marsh and marsh-mangrove ecotones losing elevation $(-1.67 \pm 0.39 \mathrm{~mm} / \mathrm{yr}$ and $6.45 \mathrm{~mm} / \mathrm{yr} \pm 2.10$, respectively), mangrove-dominated areas gaining elevation $(4.36 \mathrm{~mm} / \mathrm{yr} \pm 0.31)$, and brackish marsh experiencing no change in elevation $(0.00 \mathrm{~mm} / \mathrm{yr} \pm 0.67)$ (Howard et al. 2020).

The Grand Bay estuary, which contains the Grand Bay National Estuarine Research Reserve (GNDNERR) and Grand Bay National Wildlife Refuge, is a relatively undeveloped coastal wetland complex in the north-central Gulf of Mexico adjacent to the Mississippi-Alabama border. The GNDNERR was established in 1999 and was later designated as a marine protected area. The system is unique due to its low level of anthropogenic development and lack of freshwater inflow. Riverine inputs to the estuary ceased several thousand years ago at which time the system became a retrograding delta with high erosion rates (Otvos 2007). Shoreline erosion rates for the estuary from 1848 - 2017 ranged from $0.1-6.5 \mathrm{~m} / \mathrm{yr}$ (Terrano et al. 2019). A long-term monitoring program was established in 2011 to understand changes in elevation, accretion, and marsh vegetation communities as part of the National Estuarine Research Reserve System Sentinel Site Monitoring Network. Data generated from this program will provide important information to guide conservation and management activities in a historically understudied geographic region.

The objectives of this study were to quantify trends in surface elevation change and accretion among different marsh zones spanning a coastal elevation gradient within the Grand Bay estuary. Further, we compared elevation change rates to short-, medium-, and long-range water level rise (WLR) rates. Accomplishing these objectives should improve our understanding of elevation trends and the potential impacts of SLR, while also enhancing our understanding of potential drivers of variability in elevation maintenance within and among wetlands of the Gulf Coast.

\section{Methods}

Study Area

The GNDNERR is in southeastern Mississippi in Jackson County (Fig. 1) with a total area of approximately 7,400 ha. The Reserve is within the Coastal Streams Basin Watershed and contains a variety of habitats including, but not limited to, salt marsh, salt pannes, bays, bayous, wet pine flatwoods, coastal bayhead swamps, freshwater marshes, and maritime forests. Tides are primarily wind-driven with an average tidal range of approximately $0.6 \mathrm{~m}$ (Dillon and Walters 2007) and water depths ranging from 0.5 - $3 \mathrm{~m}$ (Otvos 2007). Water 
91 column salinity across the Reserve ranges from $0-33.5$ psu depending on site and season, with an overall median of

9220 psu from $2004-2020$ (Grand Bay National Estuarine Research Reserve, unpublished data).

93 While most intertidal marshes at the GNDNERR are dominated by black needlerush (Juncus roemerianus),

94 several habitat types are represented along the coastal transition from open water to upland habitats. A transect

95 spanning the coastal transition was established that extends from open water at its southernmost extent, through low-

96 , mid-, and high-elevation brackish marshes, and into a slash pine (Pinus elliottii) forest at its northern extent. Along

97 the transect, five sites were selected for establishment of Surface Elevation Tables (SETs) and marker horizon (MH)

98 plots that cover the full range of wetland types found across the elevation gradient. These sites included a low

99 elevation marsh dominated by smooth cordgrass (Spartina alterniflora) interspersed with small stands of $J$.

100

101

roemerianus (SPAL), two mid-elevation marshes dominated by J. roemerianus (JURO Low and JURO Mid), a

102

slightly higher elevation $J$. roemerianus marsh along the marsh-upland boundary that contains several salt pannes

(JURO High), and a relatively diverse site containing a variety of herbaceous and woody species including dense

103

stands of sawgrass (Cladium jamaicense) surrounded by slash pine (Pinus elliottii) (CLMAJ). The CLMAJ site is

105

infrequently inundated by tides but represents a potential corridor for marsh migration. All sites are densely

vegetated with little evidence of marsh die-back, except for the salt pannes at JURO High. Geographic coordinates,

106 NAVD88 elevation, and vegetation community information for each site are provided in Table 1.

107

108

109

Table 1. Site characteristics for locations within the Grand Bay National Estuarine Research Reserve chosen for placement of Surface Elevation Tables (SETs) and marker horizon (MH) plots monitored from 2012 - 2016.

\begin{tabular}{|c|c|c|c|c|}
\hline Site & Latitude & Longitude & Elevation $^{\mathrm{a}}$ & Dominant vegetation ${ }^{\mathrm{b}}$ \\
\hline CLMAJ-1 & 30.40998 & -88.41356 & 0.599 & \multirow{3}{*}{$\begin{array}{l}\text { Cladium jamaicense, Spartina patens, } \\
\text { Dicanthelium spp. }\end{array}$} \\
\hline CLMAJ-2 & 30.40961 & -88.41356 & 0.575 & \\
\hline CLMAJ-3 & 30.40940 & -88.41351 & 0.607 & \\
\hline JURO High-1 & 30.39993 & -88.41392 & 0.163 & \multirow{3}{*}{$\begin{array}{l}\text { Juncus roemerianus, Spartina patens, Borrichia } \\
\text { frutescens }\end{array}$} \\
\hline JURO High-2 & 30.39995 & -88.41425 & 0.170 & \\
\hline JURO High-3 & 30.39997 & -88.41392 & 0.111 & \\
\hline JURO Mid-1 & 30.39767 & -88.41349 & 0.040 & \multirow{3}{*}{$\begin{array}{l}\text { Juncus roemerianus, Fimbristylis spp., } \\
\text { Distichilis spicata, Borrichia frutescens }\end{array}$} \\
\hline JURO Mid-2 & 30.39798 & -88.41351 & 0.099 & \\
\hline JURO Mid-3 & 30.39828 & -88.41363 & 0.143 & \\
\hline JURO Low-1 & 30.37526 & -88.41245 & 0.058 & \multirow{3}{*}{ Juncus roemerianus, Spartina alterniflora } \\
\hline JURO Low-2 & 30.37552 & -88.41247 & 0.080 & \\
\hline JURO Low-3 & 30.37576 & -88.41241 & 0.163 & \\
\hline SPAL-1 & 30.36248 & -88.41403 & 0.004 & \multirow{3}{*}{ Spartina alterniflora, Juncus roemerianus } \\
\hline SPAL-2 & 30.36231 & -88.41411 & 0.077 & \\
\hline SPAL-3 & 30.36219 & -88.41421 & 0.075 & \\
\hline
\end{tabular}

${ }^{\mathrm{a} E l e v a t i o n}$ data references the North American Vertical Datum of $1988(\mathrm{~m})$

111 bThe species listed were those most commonly encountered during vegetation surveys conducted from $2014-2016$, 112 with the site dominant indicated in bold 


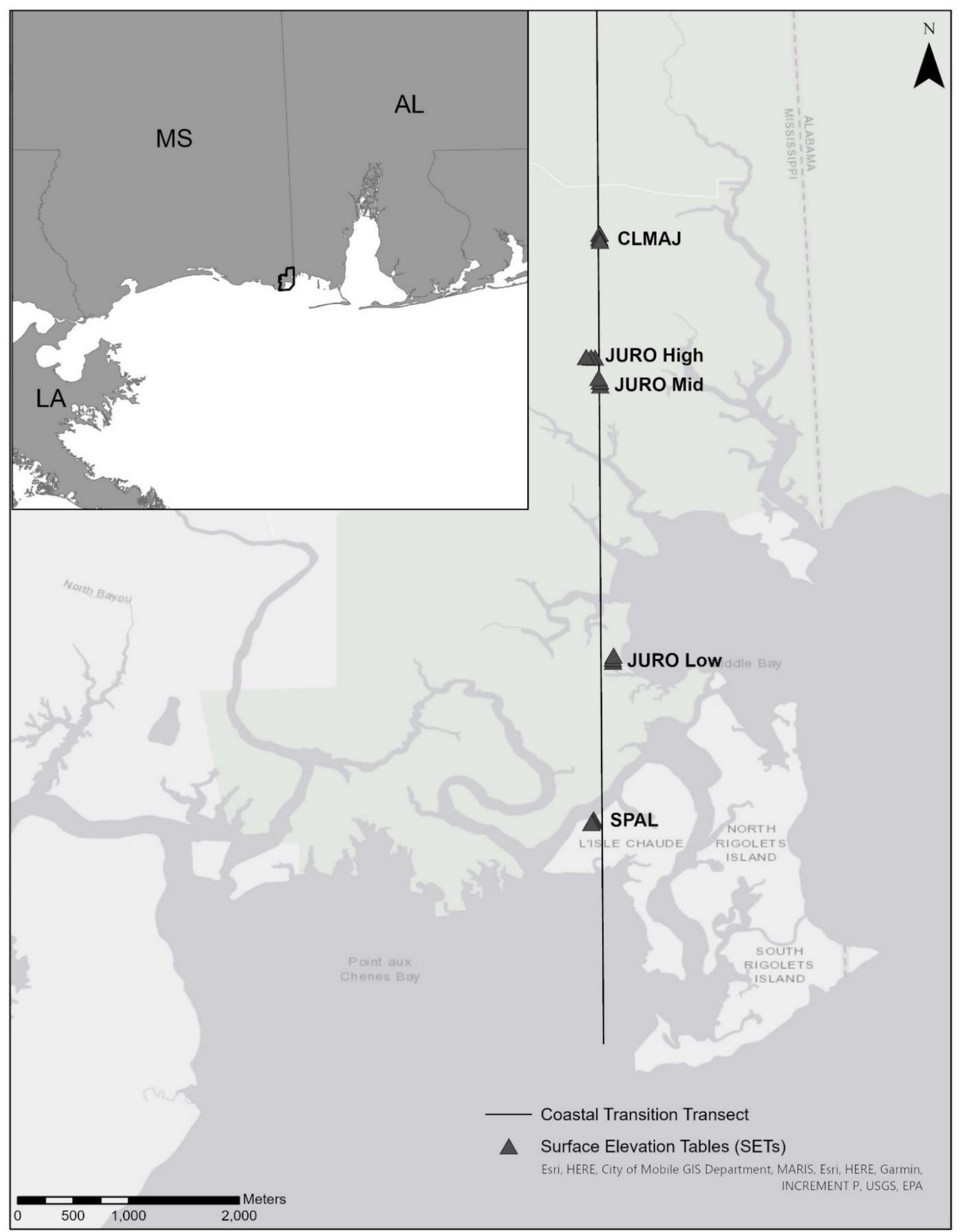

Fig. 1 Location of Surface Elevation Tables (SETs) and marker horizon (MH) plots monitored from 2012 - 2016 to quantify trends in surface elevation and accretion within the Grand Bay National Estuarine Research Reserve. Site names are shown adjacent to each site, which contains three replicate SET/MH sampling stations. The inset map shows the boundary of the Reserve and its geographic location within the north-central Gulf of Mexico 
Following procedures established in Cahoon et al. (2002), Deep rod Surface Elevation Table (SET) benchmarks were established within each site in 2011 at three locations, 20 - $40 \mathrm{~m}$ apart in similar geomorphic

121 positions (e.g., similar vegetation type, similar elevation, etc.) by driving stainless steel rods to refusal (10 - $30 \mathrm{~m})$.

122 Affixed to the end of each steel rod was a concrete collar and a receiver for SET attachment. The two-sided SET

123 arm was rotated to two positions around the receiver $\left(0^{\circ} \& 90^{\circ}\right)$ so that during each sample, a total of 36

124 measurements of marsh surface elevation were collected. Quarterly (winter (Dec - Feb), spring (Mar - May), summer (June - Aug), and fall (Sept - Nov)) measurements began in winter 2012 and continued through fall 2016 to track changes in surface position over time. The same field technician was present to read or observe the reading of SETs throughout the study period. No effort was made to remove any material on the marsh surface prior to reading SETs. Each pin was slowly lowered until it rested on the marsh surface to avoid penetrating the soil. A GPS occupation campaign involving a simultaneous static Global Navigation Satellite System (GNSS) was conducted in December 2012 to obtain North American Vertical Datum (NAVD88) elevations for each SET.

\section{Accretion monitoring}

Three feldspar MH plots $(0.5 \mathrm{~m} \times 0.5 \mathrm{~m})$ were established adjacent to each SET to measure accretion of

134 sediment and organic material. Markers were established by laying feldspar (approximately $2 \mathrm{~cm}$ thick) in each quadrat during summer 2011 (Cahoon and Turner 1989). Accretion above the marker was sampled quarterly during

136 the study period, typically at the same time SET measurements were made, by collecting soil cores that were 137 extracted from 2012 - 2014 using a cryogenic soil-coring method (Cahoon et al. 1996). However, this method was 138 abandoned in 2015 - 2016 for a simpler approach using a large knife to extract cores. In either case, a small core

139 (approximately $3 \times 3 \times 5 \mathrm{~cm}$ ) was extracted from the marsh surface and accretion was measured using Fowler Pro-

140 Max digital calipers (Newton, Massachusetts) as the minimum distance from the feldspar marker to the top of the

141 core (i.e., marsh surface) on each of four sides. Accretion was negligible (i.e., zero) if feldspar was visible on the 142 surface of the core. Feldspar was re-laid periodically if the marker was not visible after repeated samples. 
Similar to Cahoon et al. (2019), elevation and accretion rates were estimated by fitting a linear mixed model (LMM) with a random intercept using the function 'lme' in the 'nlme' package (Pinheiro et al. 2019) within

147 Program R 4.0.2 (R Core Development Team 2020). Background information regarding LMMs and their use is 148 available in Zuur et al. (2009). Parameter estimation was performed using restricted maximum likelihood (REML) 149 (Hocking 2003). Elevation change determined from SET pin readings and accretion as determined from marker horizons were treated as response variables in their respective models, and site, which was analogous to zone within the marsh (e.g., low marsh, mid marsh, etc.), was treated as a fixed effect. To account for dependence among SET measurements, random effects for SET, arm within SET, and pin within arm within SET were incorporated into the

153 LMM. For MH models, random effects were incorporated for SET, plot within SET, and measurement within plot 154 within SET. Total accretion for a given period was regressed on the number of days since feldspar application (not on the actual date of feldspar application) to account for the varied timing of feldspar re-application between plots over the sampling period. To compare mean rates of change for zones, we constructed $95 \%$ confidence intervals 157 using the function 'glht' in the R package 'multcomp' to adjust p-values and confidence intervals to control the family-wise error rate (Hothorn et al. 2008; Bretz et al. 2010). A priori significance for these tests was set at $\alpha<0.05$. While unadjusted SET and MH measurements were used in statistical models as described above, slight modifications of the SET and MH data yielded more useful data visualizations. These modifications included using 161 only the longest time series of MH readings (>1,500 days), which excluded a portion of the data from JURO High, JURO Mid, and SPAL. Also, SET measurements were adjusted to be cumulative-since-baseline by 1) subtracting the first reading from all subsequent readings for each individual pin, 2) averaging the differences for the nine pins

164 within each of the arm positions for each date, and 3) averaging the arm positions, resulting in one series of cumulative change per SET.

\section{Comparisons to Water Level Rise}

Estimated elevation change rates were compared to estimated WLR rates using data from the National

169 Water Level Observing Network station at Dauphin Island Sea Lab, Dauphin Island, Alabama. The term "water

170 level rise" was used because the medium- and short-range rates we used in our comparisons were calculated from

171 less than 19 years of data (i.e., less than a metonic cycle) and thus are not technically considered sea level rise rates.

172 WLR rates were estimated using a linear model with errors that follow an autoregressive integrated moving average 
173 (ARIMA) model of order 1,0,0 (National Oceanic and Atmospheric Administration 2009). The ARIMA (1,0,0) is

174 equivalent to an autoregressive model of order 1, or AR(1) (Brockwell et al. 2016). WLR rates were based on three

175 different time scenarios: long-range (1966 - 2016), medium-range (1998 - 2016), and short-range (2012 - 2016).

176 The corresponding rate estimates of WLR were $3.50 \mathrm{~mm} / \mathrm{yr}$ (95\% CI: 2.88 - 4.11), $6.97 \mathrm{~mm} / \mathrm{yr}$ (95\% CI: 3.31 -

177 10.64), and $13.71 \mathrm{~mm} / \mathrm{yr}(95 \% \mathrm{CI}:-2.38$ - 29.81) for long, medium, and short-range rates, respectively. Note that

178 shorter time series are composed of fewer observations; therefore, the corresponding parameter estimates will have a

179 higher degree of uncertainty, resulting in wider confidence intervals and less powerful hypothesis tests.

The elevation change rate for each site was compared to the WLR estimate from each of the three scenarios

181 via an asymptotic Z-test, which is a preferred alternative to the common practice of determining significance based

182 on whether corresponding confidence intervals overlap (Schenker and Gentleman, 2001). Resulting p-values were

183 adjusted using Holm's method (Holm 1979). Standard errors for the WLR estimates were obtained from their

184 respective ARIMA models, while standard errors for the rate of elevation change at each site were obtained from the

185 LMMs. A priori significance for these tests was set at $\alpha<0.05$.

186

187 Results

188 Elevation and accretion trends

Elevation change rates ranged from $0.54 \mathrm{~mm} / \mathrm{yr}(95 \% \mathrm{CI}:-0.63-1.72)$ at JURO High to $5.45 \mathrm{~mm} / \mathrm{yr}(95 \%$

CI: 4.27 - 6.62) at JURO Low (Fig. 2). Pairwise comparisons showed a variety of similarities and differences across sites. Notable findings included a significantly lower elevation change rate at JURO High compared to other sites except for JURO Mid (2.46 mm/yr; 95\% CI: 1.29 - 3.64). Also, elevation change rates at JURO Low, SPAL (5.00

$193 \mathrm{~mm} / \mathrm{yr} ; 95 \% \mathrm{CI}: 3.82$ - 6.17), and CLMAJ (4.27 mm/yr; 95\% CI: 3.10 - 5.45) were not statistically different from 194 each other.

Accretion rates ranged from $0.82 \mathrm{~mm} / \mathrm{yr}(95 \% \mathrm{CI}:-0.16-1.80)$ at JURO Mid to $3.89 \mathrm{~mm} / \mathrm{yr}(95 \% \mathrm{CI}: 2.90$

- 4.89) at JURO High. Pairwise comparisons showed that JURO High was significantly different from JURO Mid 


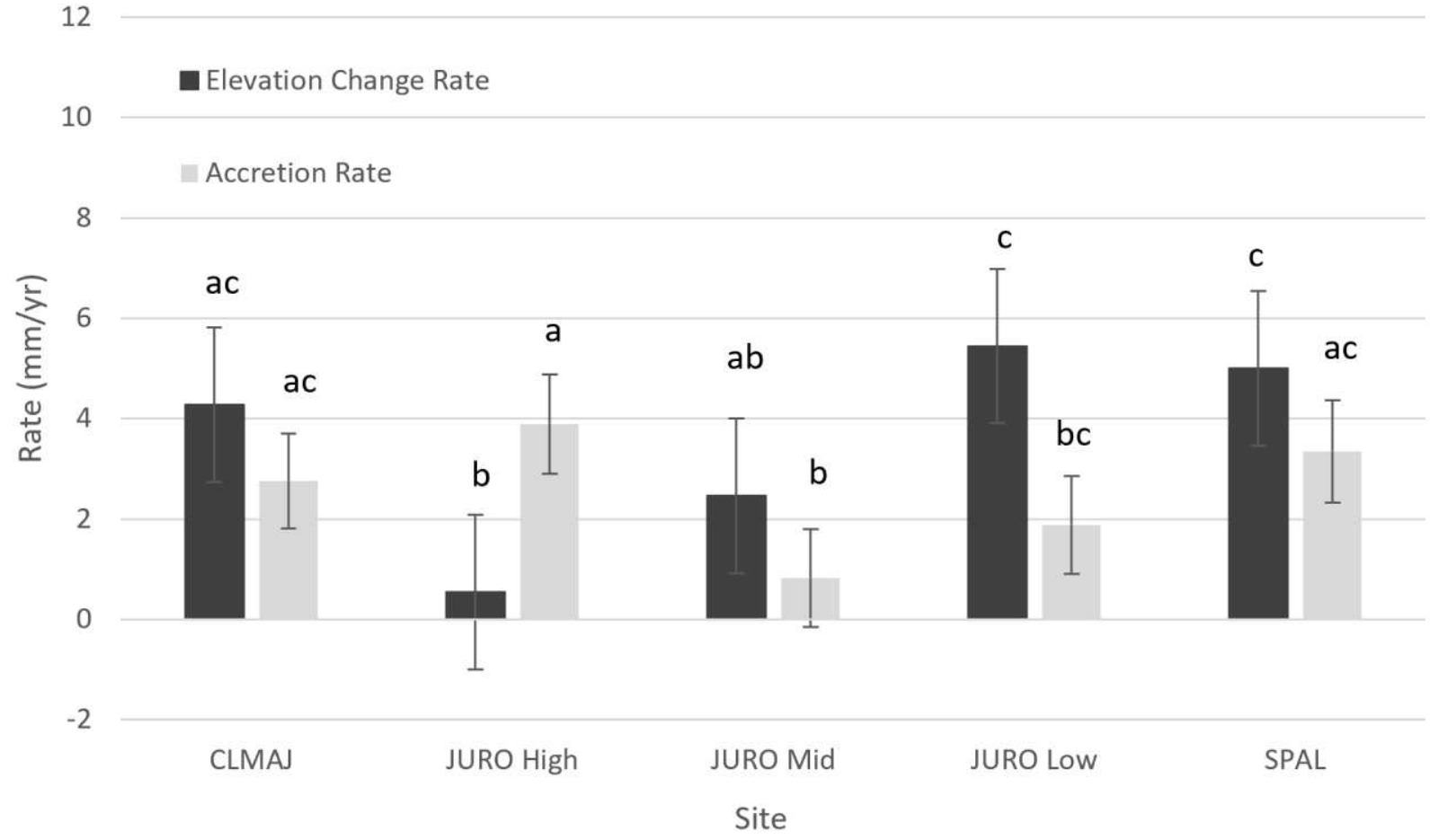

Fig. 2 Elevation change and accretion rates along a coastal elevation gradient from 2012 - 2016 within the Grand Bay National Estuarine Research Reserve. Error bars show 95\% confidence intervals and letters above each bar denote groupings determined by pairwise comparisons for elevation change or accretion rates. A priori significance for these tests was set at $\alpha<0.05$

Elevation and accretion showed similar trajectories across the study period, with some notable exceptions

(Fig. 3). For example, accretion at JURO High was consistently higher and had greater variation than elevation

change throughout the study period. Elevation at JURO Low increased consistently from $2012-2016$, except for a prominent drop in 2014 when accretion was higher than elevation change across all three SET plots. Elevation and accretion trajectories at the other sites (i.e., CLMAJ, JURO Low, and SPAL) were similar suggesting that accretion was a major driver of elevation change across the study period at these sites. 

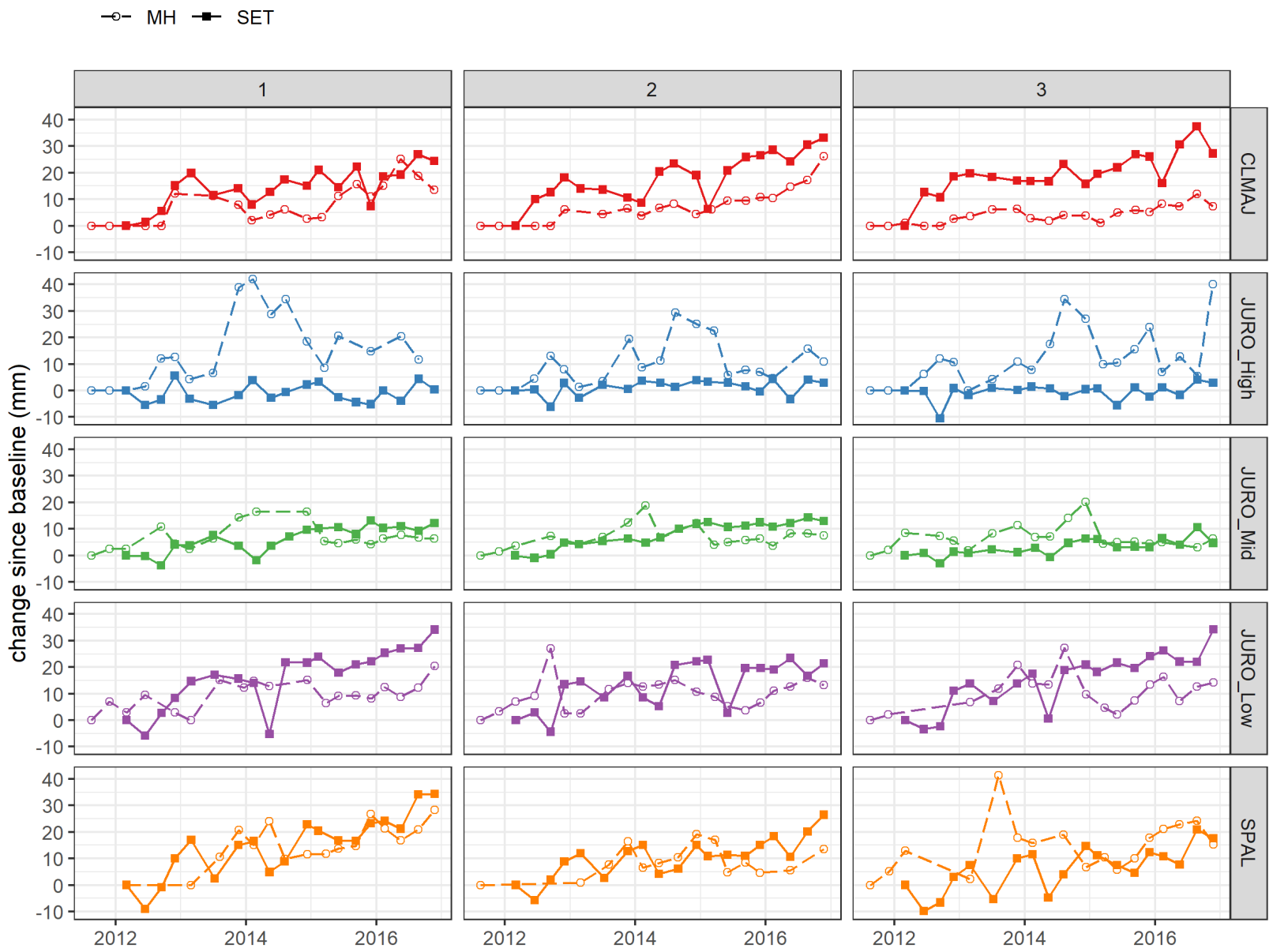

Fig. 3 Change in marsh elevation and accretion from baseline as determined by Surface Elevation Table (SET) and marker horizon (MH) measurements from five sites along an elevation gradient from 2012 - 2016 in the Grand Bay National Estuarine Research Reserve. The y-axis shows the change in elevation or accretion from baseline (i.e., zero) when the monitoring program began. The $\mathrm{x}$-axis shows the date measurements were taken. Site names are shown on the right side of the figure. The three replicate SET/MH plots at each site are designated by the numbers across the top of the figure (i.e., 1, 2, and 3)

\section{Comparisons to Water Level Rise}

The elevation change rate at JURO High was significantly lower $(P<0.001)$ than the long-range WLR rate of $3.5 \mathrm{~mm} / \mathrm{yr}(P=0.016$; Table 2$)$, while the elevation change rate at JURO Low $(5.45 \mathrm{~mm} / \mathrm{yr}$; $95 \%$ CI: 4.272 -

225 from long- range WLR. JURO High was the only site with a significantly lower elevation change rate compared to 226 the medium-range WLR rate $(6.97 \mathrm{~mm} / \mathrm{yr} ; P=0.005)$. No sites had elevation change rates that were significantly different from short-range WLR. 
Table 2. Elevation change rates, 95\% confidence intervals, and Holm-adjusted P-values (Holm 1979) from Z-tests comparing elevation change rates from five sites along an elevation gradient in the Grand Bay National Estuarine Research Reserve to three water level rise (WLR) rate estimates calculated using data from a National Water Level Observing Network station at Dauphin Island Sea Lab, Dauphin Island, Alabama. WLR rates were $3.50 \mathrm{~mm} / \mathrm{yr}(1966-2016), 6.97$

$231 \mathrm{~mm} / \mathrm{yr}(1998-2016)$, and $13.71 \mathrm{~mm} / \mathrm{yr}(2012-2016)$. Confidence intervals (95\% CI) for WLR rates are also provided. Arrows indicate significance $(\alpha<0.05)$ and the relation of the elevation change to WLR (i.e., $\downarrow$ means the rate of elevation change was significantly lower than WLR rate, while $\uparrow$ indicates it was higher than WLR rate).

\begin{tabular}{|c|c|c|c|c|c|}
\hline \multirow[t]{2}{*}{ Site } & \multicolumn{2}{|c|}{ SET Elevation Change } & \multirow{2}{*}{$\begin{array}{l}\text { Long-range WLR: } 3.50 \\
(95 \% \text { CI: } 2.88-4.11) \\
\text { p-value }\end{array}$} & \multirow{2}{*}{$\begin{array}{l}\text { Medium-range WLR: } 6.97 \text { (95\% } \\
\text { CI: 3.31-10.64) } \\
\text { p-value }\end{array}$} & \multirow{2}{*}{$\begin{array}{l}\text { Short-range WLR: } 13.71(95 \% \\
\text { CI -2.38-29.81) } \\
\text { p-value }\end{array}$} \\
\hline & Rate $(\mathrm{mm} / \mathrm{yr})$ & $\mathrm{CI}$ & & & \\
\hline CLMAJ & 4.272 & $3.098-5.447$ & 0.253 & 0.508 & 0.755 \\
\hline JURO High & 0.544 & $-0.630-1.718$ & $\downarrow<0.001$ & $\downarrow 0.005$ & 0.549 \\
\hline JURO Mid & 2.462 & $1.288-3.636$ & 0.249 & 0.087 & 0.688 \\
\hline JURO Low & 5.447 & $4.272-6.621$ & $\uparrow 0.016$ & 0.629 & 0.755 \\
\hline SPAL & 4.996 & $3.821-6.170$ & 0.081 & 0.629 & 0.755 \\
\hline
\end{tabular}




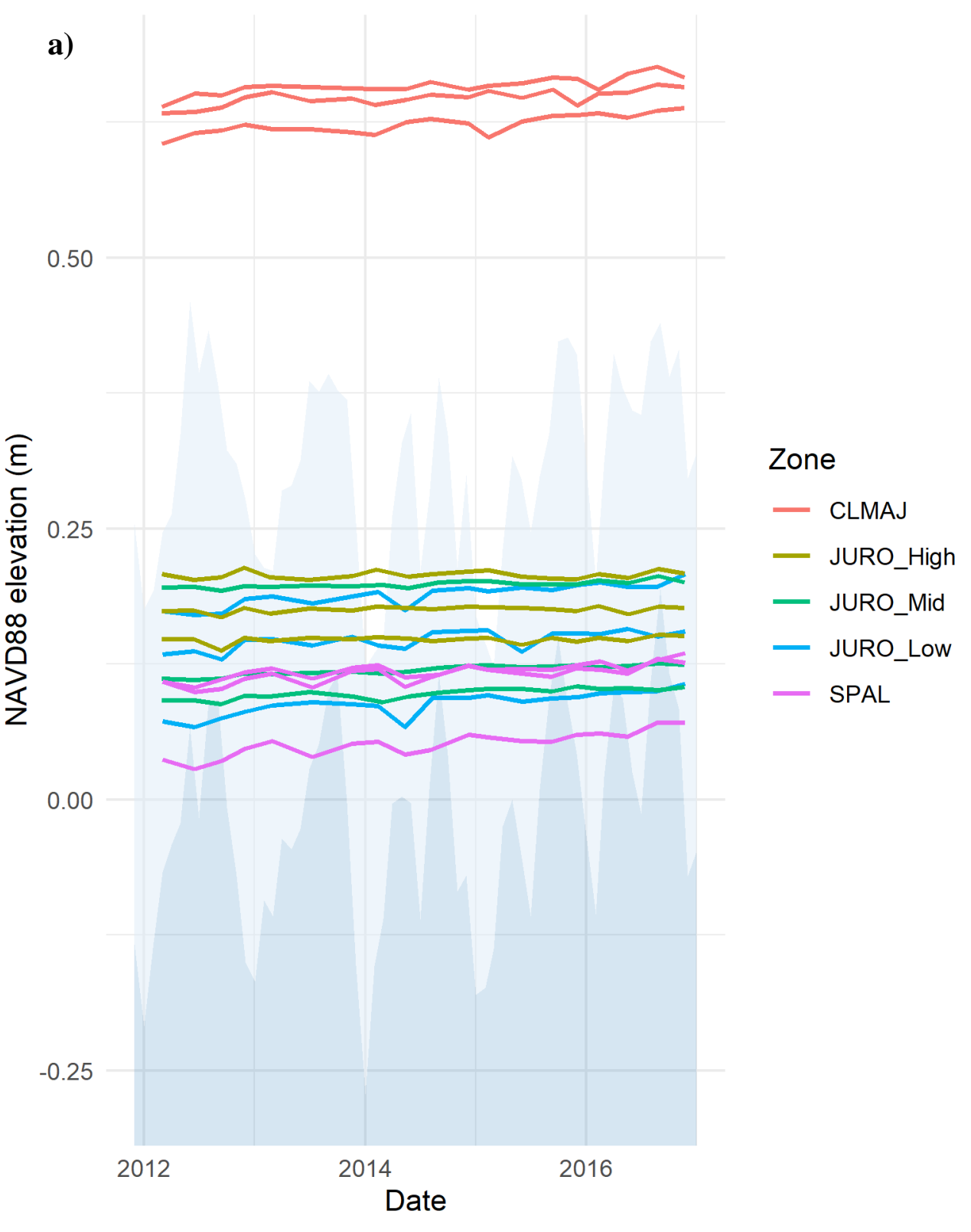

235 


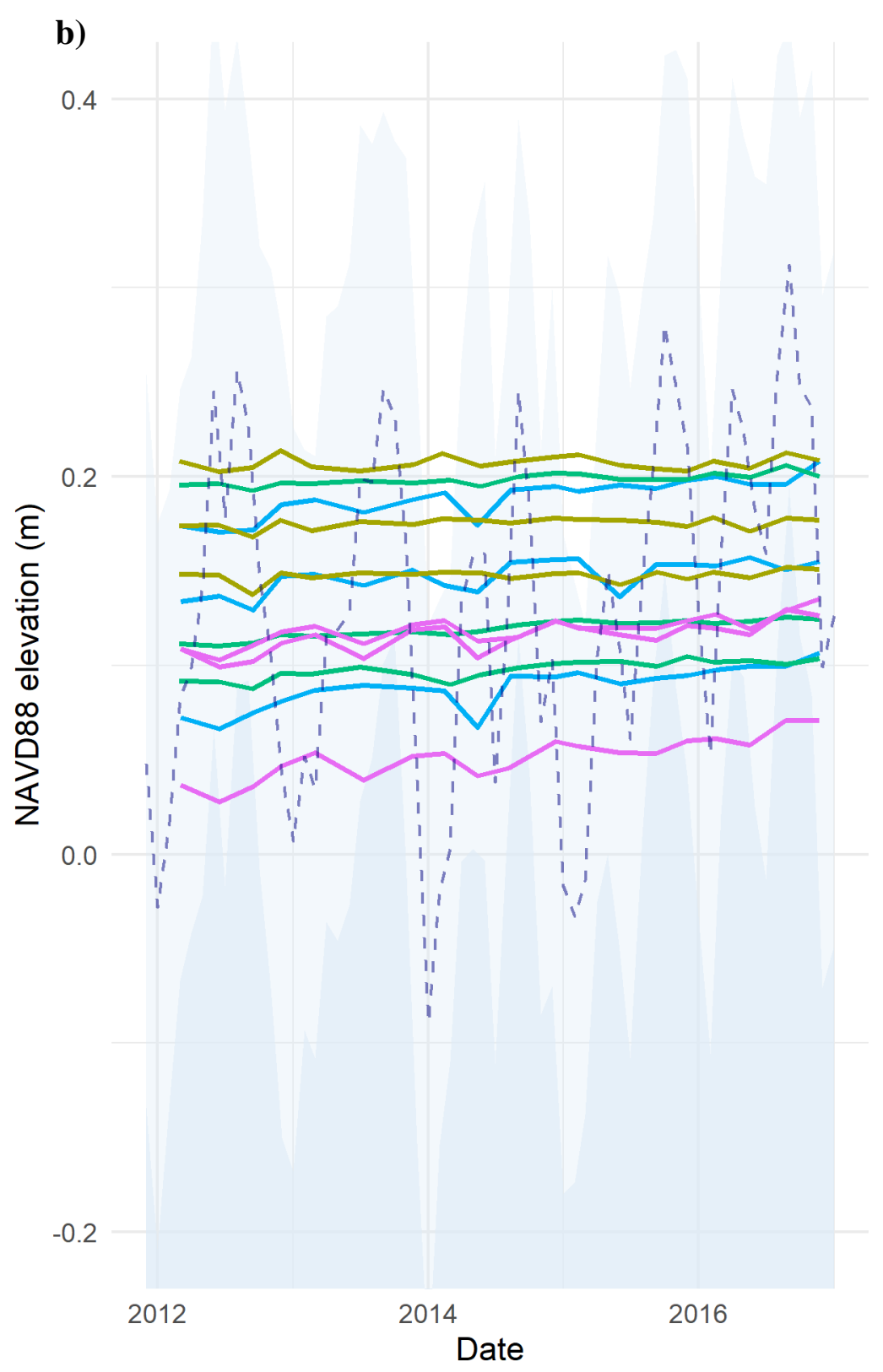

Fig. 4 Elevation change rates for a) all sites along an elevation gradient and b) the four lowest elevation sites in the Grand Bay National Estuarine Research Reserve from 2012 - 2016. Lines represent the mean elevation of each surface elevation table (SET) relative to a baseline measurement. Each line is anchored at the SET's NAVD88 elevation on the y-axis. The dashed line represents mean sea level, and the darker and lighter blue shading are monthly mean low water and high water, respectively. Monthly mean water levels were downloaded from the National Water Level Observing Network station at Dauphin Island Sea Lab, Dauphin Island, Alabama

\section{Discussion}

\section{Elevation change and accretion rates}

Different elevation change rates among sites in this study suggest that position in the tidal frame is related to marsh vulnerability to SLR in a retrograding deltaic system. Marshes higher in the tidal frame dominated by $J$. 
roemerianus appear to be the most vulnerable to SLR, as was evident when comparing elevation change at mid and high marsh with WLR rates. Inundation frequency of mid and high marsh could be increasing because average monthly mean high water, mean sea level, and mean low water (MLW) impacted these sites more frequently across the study period (e.g., average monthly MLW exceeded the elevation at JURO High in 2016) (Fig. 4). Aerial imagery from these areas in 1968 compared to 2016 shows a $>40 \%$ reduction in the spatial extent of salt pannes

254 (i.e., roughly 11.7 acres in 1968 compared to 6.8 acres in 2016) (Fig. 5). Relatively low elevation change rates and 255 shifts in the areal extent of salt pannes could be the result of increased inundation coupled with limited sediment delivery for elevation maintenance. Sedimentary inputs to the Grand Bay estuary from upland sources occur

257 primarily through two small drainages (i.e., Bayou Heron and Bayou Cumbest) and overland flow (i.e., sheet flow)

258 (Otvos 2007). JURO High and Mid are also >1000 $\mathrm{m}$ from an open water embayment, Middle Bay, and $>400 \mathrm{~m}$

259 from Middle Bayou to the west. This suggests that high marshes with limited potential for sediment delivery could experience higher inundation frequency similar to mid-marsh if SLR rates increase as predicted for this region. It

261 should be noted that this hypothesis is not supported by a relatively high accretion rate at JURO High, which is 262 discussed below.

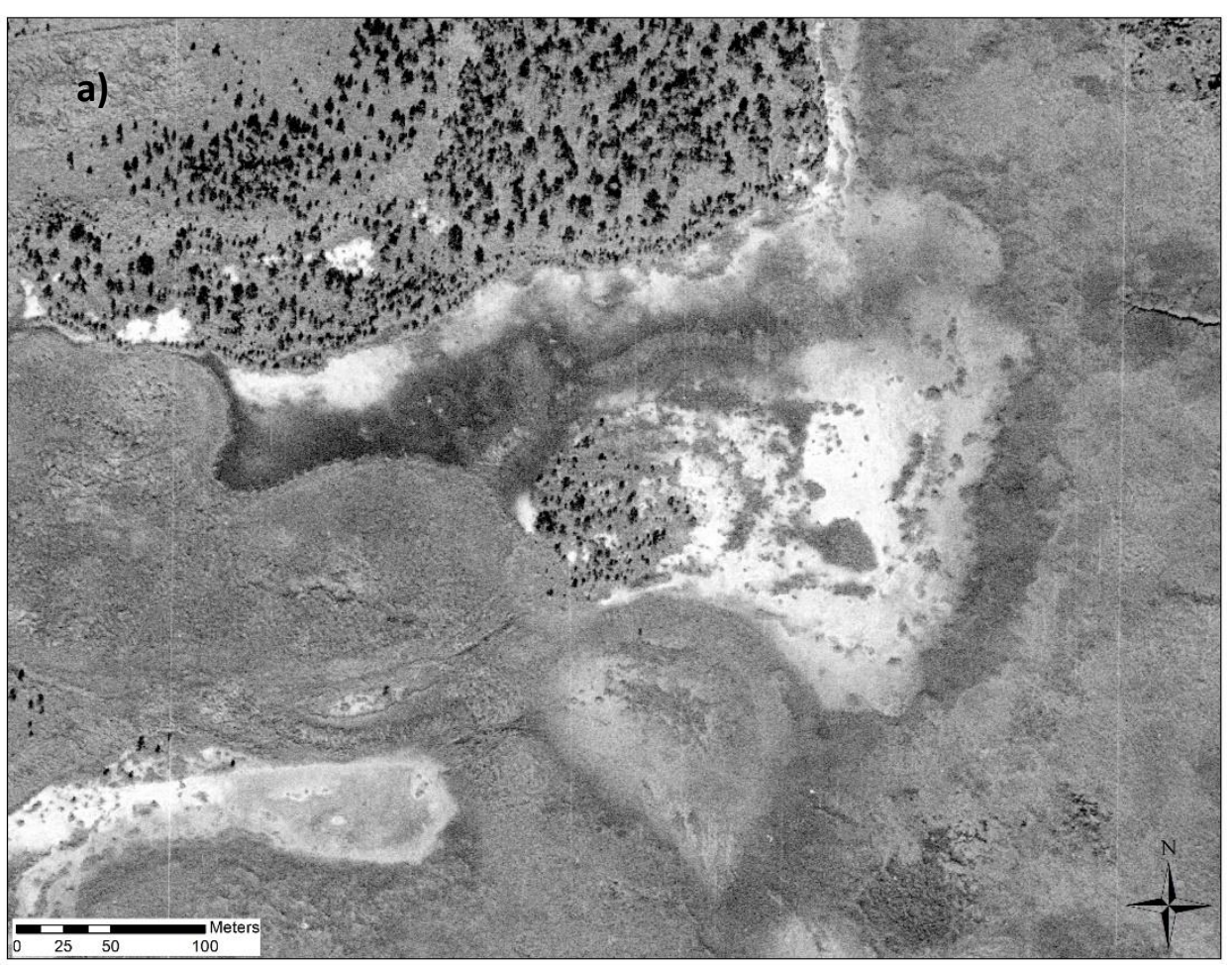




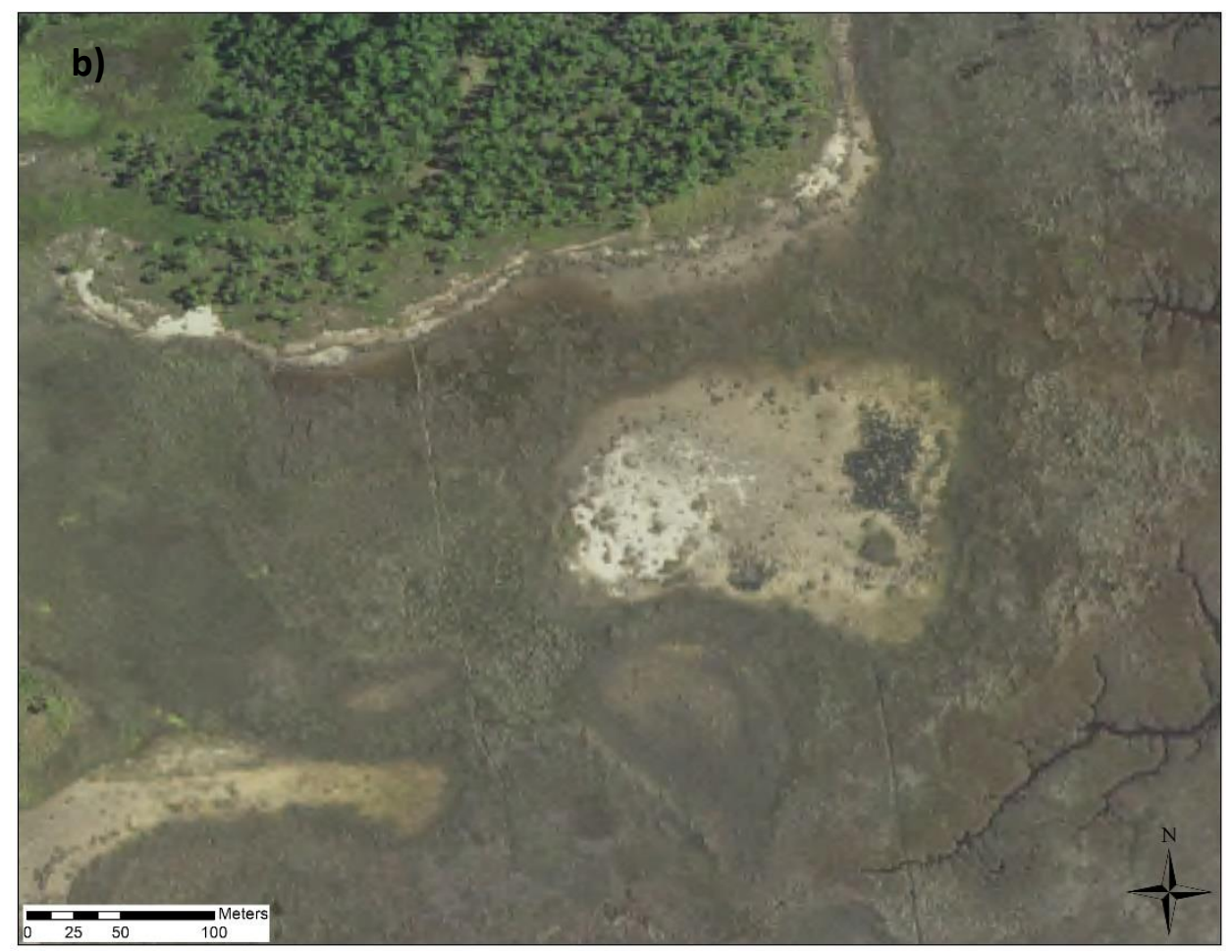

Fig. 5 Aerial images of the JURO High and JURO Mid sites in a) 1968 (Mississippi Department of Marine Resources, 2008) compared to b) 2016 (Office for Coastal Management Partners, 2021) in the Grand Bay National Estuarine Research Reserve

Accretion rates and temporal variation in accretion at JURO High was higher than at all other sites (3.89 $\mathrm{mm} / \mathrm{yr}$; $95 \% \mathrm{CI}: 2.59-5.19$ ). One explanation is that this site is near an erosional scarp where a salt panne transitions to a slash pine flatwood. The nearby scarp could be a source of sediment when storm-induced high tides recede and/or heavy rains occur. Another explanation relates to soil composition. Surface Elevation Tables at JURO High were installed in a narrow band of salt pannes bordered by a dense stand of $J$. roemerianus to the south and a slash pine upland to the north (Fig. 5). Soil samples collected adjacent to JURO High SETs in 2017 were identified as fine-silty, mixed epiaquepts and epiaquents (United States Department of Agriculture 1999), which were unique among the SET/MH plots at Grand Bay (Natural Resources Conservation Service, unpublished data). These soils are likely more susceptible to fracturing from wet-dry cycling, flocculation, and/or salinity and sodicity effects that could cause feldspar to migrate into deeper soil horizons (Page Sanderson, personal communication), which may have led to higher apparent accretion rates noted in this study.

Elevation change rates were highest in the low marshes, dominated by J. roemerianus or S. alterniflora, where JURO Low and SPAL gained elevation at higher rates than the long-range WLR rate $(3.50 \mathrm{~mm} / \mathrm{yr})$. The 
mechanisms through which low marshes maintain elevation may differ depending on the vegetation community. For example, the elevation change rate to accretion rate ratio at JURO Low was 0.34 compared to 0.67 at SPAL, suggesting that accretion is a major driver of elevation change in low marsh habitats dominated by $S$. alterniflora while subaerial processes are major drivers of elevation change at low elevation marshes dominated by $J$. roemerianus. Further support for this hypothesis is that belowground biomass collected from JURO Low in 2015 $\left(5,527 \mathrm{~g} / \mathrm{m}^{2}\right)$ was higher (though not significant) than at SPAL $\left(3,989 \mathrm{~g} / \mathrm{m}^{2}\right)$ (Archer et al. 2021). This finding agrees with other studies documenting that $J$. roemerianus root production is a major driver of marsh elevation maintenance in frequently inundated marshes (Wu et al. 2020; Turner 1990).

\section{Elevation maintenance}

Marsh persistence may depend on stimulated biomass production as inundation rates increase. Although less studied historically than abiotic processes (e.g., accretion), biotic feedbacks are an important component of marsh habitats that allow them to keep pace with rising sea levels. These biotic processes include indirect (e.g.,

297 sediment trapping by marsh vegetation) and direct (e.g., accumulation of organic material, root production) feedbacks to elevation (Cahoon et al. 2006). For example, changes in atmospheric conditions associated with

299 climate change or nutrient enrichment could also result in greater belowground production. Mesocosm experiments

300 in Louisiana have shown that increases in $\mathrm{CO}_{2}$ can reduce salinity stress and increase shoot-base expansion in a $\mathrm{C}_{3}$

301 species (Schoenoplectus americanus) (Cherry et al. 2009), while field studies in the Chesapeake Bay area

302 demonstrated that a combination of elevated $\mathrm{CO}_{2}$ and nitrogen addition resulted in the greatest rates of elevation 303 gain through root zone expansion (Langley et al. 2009). Juncus roemerianus, also a $\mathrm{C}_{3}$ species, is often dominant in 304 marshes in the north-central Gulf of Mexico. Future increases in atmospheric $\mathrm{CO}_{2}$ could promote subsurface 305 biomass production in J. roemerianus, helping marshes maintain elevation as sea level rises.

Accretionary inputs to lower marshes in Grand Bay were relatively high despite limited sediment delivery

307 from upland sources. Considering that most southeastern facing shorelines in Grand Bay have erosion rates that 308 exceed $0.5 \mathrm{~m} / \mathrm{yr}$ (Terrano et al. 2019), shoreline erosion may be an important source of sediment for marsh elevation 309 maintenance in low marsh habitats. Smith et al. (2021) measured sediment accumulation on the marsh platform in 310 relation to the quantity of eroded sediment from adjacent shorelines in Grand Bay. They found that sediment 311 deposition along erosional edges was typically concentrated within $10 \mathrm{~m}$ of the vertical escarpment along the marsh 
edge, which agrees with other research along the Gulf Coast that has shown high rates of deposition within $10 \mathrm{~m}$ of the water-marsh boundary (Leonard et al. 1995). However, during larger erosion events, Smith et al. (2021) noted a lack of deposition in nearshore areas. They hypothesized that larger erosive events exceed an "erosion threshold," where sediment is no longer deposited within $10 \mathrm{~m}$ of the marsh edge, but instead is transported to other areas in the estuary. All the sites in this study were further than $10 \mathrm{~m}$ from the marsh edge (e.g., SETs/MH plots at SPAL were

317 the closest to the marsh edge at $20-45 \mathrm{~m}$ away). As such, marsh accretion at these sites could be driven by less

318 frequent, pulse events that erode sediment from the marsh edge, transport it inland, and deposit it on the marsh platform, similar to what was hypothesized by Smith et al. (2021). Sedimentary inputs from storm events have been shown to mitigate marsh subsidence by providing elevation capital in other areas as well. Hurricane Katrina, for example, deposited an average of $5.18 \mathrm{~cm}$ of sediment in the deltaic plain of Louisiana (Turner et al. 2006), which resulted in elevation gains in otherwise subsiding marshes at Big Branch and Pearl River, Louisiana (7 mm and 17 mm, respectively) (McKee and Cherry 2009).

\section{Potential limitations}

Reliance on SET and MH data for predicting marsh persistence has been criticized by some. For example, Kirwan et al. (2016) indicated that accretion rates at high elevation marshes are not useful predictors. Their metaanalysis suggested that most marshes will maintain elevation, even under high SLR scenarios and point to a common over-estimation of marsh instability in the literature. They also emphasized the ability of marshes to migrate inland and maintain elevation through biophysical feedbacks. Marshes that are most likely to be submerged

331 are those with an accretion deficit (i.e., elevation or accretion rate minus SLR) greater than $0.5 \mathrm{~mm} / \mathrm{yr}$. Marshes at JURO High and Mid have accretion deficits that exceed this threshold, even for the long-range SLR scenarios (2.96 and $1.04 \mathrm{~mm} / \mathrm{yr}$, respectively when using the long-range WLR of $3.5 \mathrm{~mm} / \mathrm{yr}$ ). According to Kirwan et al. (2016), a closer look at frequently flooded marshes may provide more insight about vulnerability as accretion rates will increase sharply if marshes are in jeopardy of submerging. The lack of a sufficient period of record precludes a reliable assessment of accretion rates in Grand Bay, but the results presented in this manuscript can serve as a

337 baseline from which to compare accretion rates over longer periods of time. 
$\mathrm{mm} / \mathrm{yr}$ in Eugene Island, LA and generally decrease moving east towards a geologically stable gauge at Pensacola,

341 FL, which has a long-range rate of $2.53 \mathrm{~mm} / \mathrm{yr}$ (Turner 1990). The long-range WLR rate at the closest gauge to

342 Grand Bay, MS at Dauphin Island, AL has risen from $3.5 \mathrm{~mm} / \mathrm{yr}$ (used in our analyses for 2012 - 2016) to 4.13

$343 \mathrm{~mm} / \mathrm{yr}$ in 2020 (National Oceanic and Atmospheric Administration 2021), which shows that WLR rates are

344 increasing even over short timescales. However, the short-range WLR rate that was used in this study (13.71 mm/yr)

345 was not significantly different when compared to elevation change rates from any of the sites because of the wide

346 confidence interval (95\% CI: $-2.38-29.81)$. With an increased emphasis on modeling marsh response to increases

347 in sea level, it is important to recognize that longer periods of record are needed to better define WLR rates when

348 predicting marsh vulnerability. This approach would reduce the amount of uncertainty in predictions, which would

349 enhance marsh restoration planning and conservation.

Modeling sediment dynamics and marsh persistence in Grand Bay estuary

Substantial research has been done to understand sediment and vegetation dynamics and project future conditions for the Grand Bay estuary (Passeri et al. 2015; Raposa et al. 2016; Alizad et al. 2018; Wu et al. 2017; Wu et al. 2020; Nowacki and Ganju 2020; Archer et al. 2021), with long-term projections suggesting that Grand Bay marshes will experience large changes in the coming decades with the magnitude of SLR being an important 356 determinant of marsh persistence. Passeri et al. (2015) used a hydrodynamic modeling approach that included 357 historical changes in sea level and geomorphology. They determined that the estuary has become increasingly ebb 358 dominant over the last 150 years. The determination of ebb dominance helps to explain high erosion rates 359 documented for many seaward shorelines over a similar timeframe (Terrano et al. 2019). Nowacki and Ganju (2020) 360 measured sediment flux in several locations within the estuary in 2016 and determined that Grand Bay is a "self361 cannibalizing" sedimentary system with the bulk of suspended sediment leaving the system and only a small portion 362 being available for maintaining marsh elevation. Assessments of marsh resilience to sea level rise (MARS) have 363 shown that low tidal range and accretion rates are risk factors for marsh resilience (Raposa et al. 2016). Grand Bay, 364 being a microtidal system with low rates of sediment accretion, falls into a high-risk category overall for the MARS 365 index. However, two metrics used in MARS, percentage of marsh in the lowest third of the estuary and elevation change rate, were scored as low risk for Grand Bay. 
Archer et al. (2021) used updated measures of above- and belowground biomass characteristics in the Marsh Equilibrium Model (MEM) (Morris et al. 2002) to estimate inundation time at SPAL, JURO Low, and JURO

369 High over the next 100 years for three SLR scenarios: $3.74 \mathrm{~mm} / \mathrm{yr}, 7.0 \mathrm{~mm} / \mathrm{yr}$, and $20.0 \mathrm{~mm} / \mathrm{yr}$. The results showed 370 that a $3.74 \mathrm{~mm} / \mathrm{yr}$ SLR rate over the next 100 years will increase inundation time $81 \%, 84 \%$, and $442 \%$ at SPAL

371 Low, JURO Low, and JURO High from current levels, respectively. Models showed that the sites will be inundated $372100 \%$ of the time in $70-90$ years when using SLR rates of $7 \mathrm{~mm} / \mathrm{yr}$, and in $40-50$ years when using a SLR rate of $37320 \mathrm{~mm} / \mathrm{yr}$. Wu et al. (2017) developed a mechanistic model that integrates the MEM and is informed by accretion 374 rates presented in this manuscript. The results included estimates of SLR rate thresholds for marsh collapse in Grand 375 Bay of 11.9 and $8.4 \mathrm{~mm} / \mathrm{yr}$ in 2050 and 2100, respectively. For example, their models showed that exceedance of a 376 SLR rate of $8.4 \mathrm{~mm} / \mathrm{yr}$ by 2100 will result in a loss of roughly $56 \%$ of wetland area. A more recent estimate reduces 377 these thresholds to 10.8 and $7.2 \mathrm{~mm} / \mathrm{yr}$ by 2050 and 2100, respectively, and stresses the importance of belowground 378 biomass for elevation maintenance and marsh persistence in the marine-dominated Grand Bay estuary (Wu et al. 379 2020). A coupled-hydrodynamic marsh model called Hydro-MEM predicts changes to marsh extent within Grand 380 Bay under four different SLR scenarios by 2100: 0.2 m, $0.5 \mathrm{~m}, 1.2 \mathrm{~m}$, and $2 \mathrm{~m}$ (Alizad et al. 2018). There was a 381 predicted increase in marsh extent for all scenarios from current levels (e.g., current marsh extent was estimated at 3823,612 ha versus 3,800 ha in 2100). However, predicted marsh expansion assumes successful migration of marshes 383 into current upland areas as much of the current marsh footprint is predicted to become open water by 2100 , especially in the higher SLR scenarios.

\section{Management Implications}

Grand Bay marshes face many challenges for persistence in their current footprint (e.g., shoreline erosion, ebb-dominance, etc.). While the diminishment of a retrograding delta is a natural process, Grand Bay is one of the more pristine and undeveloped marsh ecosystems along the north-central Gulf Coast that is functionally important for many species, including humans. Future increases in SLR and exorbitant shoreline erosion rates suggest that the persistence of marsh habitats will depend on continued accretionary inputs, vegetative growth in response to SLR,

392 landward migration, and potentially the use of natural and nature-based features (NNBFs) (e.g., living shorelines, 393 thin-layer placement, reconstruction of historical barriers). Human intervention on a broad scale would carry some uncertainty. For example, rebuilding the Grand Batture Islands, a set of barrier islands that once protected the Grand 
Bay estuary from the larger Mississippi Sound, has been proposed for more than three decades as a strategy to increase habitat and protect inland marshes from erosion (Meyer-Arendt and Kramer 1991; Eleuterius and Criss 1991). However, hydrodynamic models have shown that restoring the islands to their historic footprint would increase tidal velocities, thereby making the system more ebb-dominant (Passeri et al. 2015). The result could be an inadvertent increase in sediment export from the system, causing an acceleration of marsh loss. Constructing

400 shoreline protection structures (e.g., living shorelines) is another option, but this would also carry uncertainty 401 because shoreline hardening neglects to account for impacts on the net sediment budget (Ganju 2019) and could inhibit elevation maintenance in nearshore areas by reducing shoreline erosion (Smith et al. 2021). More research

403 needs to be done in Grand Bay and in other areas of the northern Gulf of Mexico to understand the impact of 404 NNBFs on sediment budgets, including long-term studies that incorporate increases in sea level. Future research should focus on assessing the effects of thin layer placement and/or the effects of NNBFs on sedimentary processes to better understand both the benefits and limitations of these approaches, which would inform restoration planning and implementation within the Grand Bay estuary and beyond.

For undeveloped areas like Grand Bay, marsh migration is a good option for conservation of marsh structure and function (Enwright et al. 2016). Adjacent upland habitats receive periodic applications of prescribed

410 fire, which can facilitate upslope marsh migration (Hacker 2018). The CLMAJ site represents an upland area within 411 a marsh migration corridor that receives prescribed fire. Our comparison of elevation change rate ( $4.272 \mathrm{~mm} / \mathrm{yr}$;

$41295 \%$ CI: 3.098 - 5.447) to WLR showed that the site is maintaining elevation relative to water level. Monitoring 413 efforts in this location over the long-term could prove to be valuable for understanding elevation and accretion 414 dynamics with respect to marsh migration. Regardless, more research needs to be done to better understand the current rate of marsh migration at Grand Bay with an emphasis on the marsh-upland ecotone (e.g., JURO High).

416 Research in other areas has shown that ecotones are excellent places to study SLR impacts, even over short 417 timescales (Wasson et al. 2013). Grand Bay is fortunate to have several "pine islands" adjacent to bayous that have 418 marsh-upland ecotones that are very accessible for study. These areas are the focus of several ongoing research 419 projects aimed at understanding SLR impacts. Future work could be focused on determining the rate of marsh 420 migration along the marsh-upland ecotone in a variety of areas to determine where conservation efforts (e.g., land 421 acquisition, prescribed burning) are most needed to preserve highly valued marsh functions. 
423

424

425

426

427

428

429

430

431

432

433

434

435

436

437

438

439

440

441

442

443

444

445

446

447

448

\section{References}

Alizad K, Hagen SC, Medeiros SC, Bilskie MV, Morris JT, Balthis L, Buckel CA (2018) Dynamic responses and implications to coastal wetlands and the surrounding regions under sea level rise. PloS one 13(10): e0205176

Archer MJ, Pitchford JL, Biber P, Underwood W (2021) Assessing vegetation, nutrient content and soil dynamics along a coastal elevation gradient in a Mississippi Estuary. Estuaries and Coasts. https://doi.org/10.1007/s12237-021-01012-2

Beckett LH, Baldwin AH, Kearney MS (2016) Tidal marshes across a Chesapeake Bay subestuary are not keeping up with sea-level rise. PloS one 11(7): e0159753

Borchert SM, Osland, MJ, Enwright NM, Griffith KT (2018) Coastal wetland adaptation to sea level rise: Quantifying potential for landward migration and coastal squeeze. J of Appl Ecology 55(6):2876-2887

Bretz F, Hothorn T, Westfall P (2010) Multiple Comparisons Using R. CRC Press, Boca Raton, Florida

Brockwell PJ, Brockwell PJ, Davis RA, Davis RA (2016) Introduction to time series and forecasting. Springer

Byrnes MR, Britsch LD, Berlinghoff JL, Johnson R, Khalil S (2019) Recent subsidence rates for Barataria Basin, Louisiana. Geo-Marine Letters 39(4):265-278

Cahoon DR, Turner RE (1989) Accretion and canal impacts in a rapidly subsiding wetland II. Feldspar marker horizon technique. Estuaries 12(4):260-268

Cahoon DR., Lynch JC, Knaus RM (1996) Improved cryogenic coring device for sampling wetland soils. J of Sedimentary Res, Section A: Sedimentary Petrology and Processes 66(5)

Cahoon DR, Lynch JC, Perez BC, Segura B, Holland RD, Stelly C, Stephenson G, Hensel P (2002) High-precision measurements of wetland sediment elevation: II. The rod surface elevation table. J Sedimentary Res. 72:734-739

Cahoon DR, Hensel PF, Spencer T, Reed DJ, McKee KL, Saintilan N (2006) Coastal wetland vulnerability to relative sea-level rise: wetland elevation trends and process controls. In Verhoeven JT, Beltman B, Bobbink R, Whigham DF (eds) Wetlands and natural resource management. Springer, Berlin, Heidelberg, pp 271292 
Cahoon DR, Lynch JC, Roman CT, Schmit JP, Skidds DE (2018). Evaluating the relationship among wetland vertical development, elevation capital, sea-level rise, and tidal marsh sustainability. Estuaries and Coasts 42(1):1-15

Cahoon DR, Lynch JC, Roman CT, Schmit JP, Skidds DE (2019) Evaluating the relationship among wetland vertical development, elevation capital, sea-level rise, and tidal marsh sustainability. Estuaries and Coasts 42:1-15

Cahoon DR, McKee KL, Morris JT (2021) How plants influence resilience of salt marsh and mangrove wetlands to sea-level rise. Estuaries and Coasts 44:883-898

Hocking RR (2003) Methods and applications of linear models: regression and the analysis of variance. John Wiley and Sons, New Jersey

Holm S (1979) A simple sequentially rejective multiple test procedure. Scandinavian Journal of Statistics 6:65-70 

$50(3): 346-363$

Howard RJ, From AS, Krauss KW, Andres KD, Cormier N, Allain L, Savarese M (2020) Soil surface elevation dynamics in a mangrove-to-marsh ecotone characterized by vegetation shifts. Hydrobiologia 847(4):10871106

Kirwan ML, Temmerman S, Skeehan EE, Guntenspergen GR, Fagherazzi S (2016) Overestimation of marsh vulnerability to sea level rise. Nature Climate Change 6(3):253-260

Lane RR, Day JW, Day JN (2006) Wetland surface elevation, vertical accretion, and subsidence at three Louisiana estuaries receiving diverted Mississippi River water. Wetlands 26(4):1130-1142

Langley JA, McKee KL, Cahoon DR, Cherry JA, Megonigal JP (2009) Elevated CO2 stimulates marsh elevation gain, counterbalancing sea-level rise. Proceedings of the National Academy of Sciences 106(15):61826186

Leonard LA, Hine AC, Luther ME (1995) Surficial sediment transport and deposition processes in a Juncus roemerianus marsh, west-central Florida. Journal of Coastal Research:322-336

McKee KL, Cherry JA (2009) Hurricane Katrina sediment slowed elevation loss in subsiding brackish marshes of the Mississippi River delta. Wetlands 29(1):2-15

Meyer-Arendt KJ, Kramer KA (1991) Deterioration and Restoration of the Grand Batture Islands, Mississippi. Mississippi Geology 11(4):1-5

Mississippi Department of Marine Resources (2008). Mississippi Gulf Coast Historical Aerial Photography Digital Database Development. Coastal Environments, Inc.

Morris JT, Sundareshwar PV, Nietch CT, Kjerfve B, Cahoon DR (2002) Responses of coastal wetlands to rising sea level. Ecology 83(10):2869-2877

National Oceanic and Atmospheric Administration (2009) Technical Report NOS CO-OPS 053 - Sea Level Variations of the United States 1854-2006. https://tidesandcurrents.noaa.gov/publications/Tech_rpt_53.pdf. Accessed 19 Feb 2020

National Oceanic and Atmospheric Administration Center for Operational Oceanographic Products and Services (2021) Sea level trends. https://tidesandcurrents.noaa.gov/sltrends/. Accessed 26 May 2021 
Nowacki DJ, Ganju NK (2020) Sediment Dynamics of a Divergent Bay-Marsh Complex. Estuaries and Coasts 44(5):1-15

Office for Coastal Management Partners (2021) NAIP Digital Ortho Photo Image. https://www.fisheries.noaa.gov/inport/item/49508. Accessed 15 November 2021

Osland, MJ, Griffith KT, Larriviere JC, Feher LC, Cahoon DR, Enwright NM, Oster DA, Tirpak JM, Woodrey MS, Gulf of Mexico coast: Gaps and opportunities for developing a coordinated regional sampling network. PloS one 12(9):e0183431

Otvos EG (2007) Geologic Framework and Evolutionary History. In Peterson MS, Waggy GL, Woodrey MS (eds) Grand Bay National Estuarine Research Reserve: an ecological characterization. https://grandbaynerr.org/wp-content/uploads/2010/12/Grand-Bay-National-Estuarine-Research-ReserveSite-Profile-Final-Draft-01Oct2007.pdf, pp 22-46. Accessed 23 August 2020

Passeri DL, Hagen SC, Medeiros SC, Bilskie MV (2015) Impacts of historic morphology and sea level rise on tidal hydrodynamics in a microtidal estuary (Grand Bay, Mississippi). Continental Shelf Research 111:150-158

Pinheiro J, Bates D, DebRoy S, Sarkar D, R Core Team (2019) nlme: Linear and Nonlinear Mixed Effects Models. R package version 3.1-140. https://CRAN.R-project.org/package=nlme. Accessed 18 December, 2020

Program for Local Adaptation to Climate Effects (2021) https://placeslr.org/our-products/gulf-of-mexico-setinventory/). Accessed Sept 18, 2021

R Core Development Team (2020) R: A language and environment for statistical computing. R Foundation for Statistical Computing, Vienna, Austria. https://www.R-project.org/. Accessed 28 December 2020

Raposa KB, Wasson K, Smith E, Crooks JA, Delgado P, Fernald SH, Ferner MC, Helms A, Hice LA, Mora JW, Puckett B (2016) Assessing tidal marsh resilience to sea-level rise at broad geographic scales with multimetric indices. Biological Conservation 204:263-275

Schenker N, Gentleman JF (2001) On judging the significance of differences by examining the overlap between confidence intervals. The American Statistician 55(3):182-186

Stagg CL, Krauss KW, Cahoon DR, Cormier N, Conner WH, Swarzenski CM (2016) Processes contributing to resilience of coastal wetlands to sea-level rise. Ecosystems 19(8):1445-1459 
Smith KE, Terrano JF, Khan NS, Smith CG, Pitchford JL (2021) Lateral shoreline erosion and shore-proximal sediment deposition on a coastal MARSH from seasonal, storm and decadal measurements. Geomorphology 107829

Terrano JF, Smith KEL, Pitchford J, McIlwain J, Archer M (2019) Shoreline change analysis for the Grand Bay National Estuarine Research Reserve, Mississippi Alabama—1848 to 2017 (ver. 2.0, February 2019): U.S. Geological Survey data release. https://doi.org/10.5066/P9JMA8WK. Accessed 10 October 2020

Turner RE (1990) Landscape development and coastal wetland losses in the northern Gulf of Mexico. American Zoologist 30(1):89-105

Turner RE, Baustian JJ, Swenson EM, Spicer JS (2006) Wetland sedimentation from Hurricanes Katrina and Rita. Science 314:449-452

United States Department of Agriculture (1999) Soil Taxonomy: A Basic System of Soil Classification for Making and Interpreting Soil Surveys. United States Department of Agriculture Natural Resources Conservation Service. Agriculture Handbook, Number 436:871

Wasson K, Woolfolk A, Fresquez C (2013) Ecotones as indicators of changing environmental conditions: rapid migration of salt marsh-upland boundaries. Estuaries and Coasts 36(3):654-664

Wu W, Biber P, Bethel M (2017) Thresholds of sea-level rise rate and sea-level rise acceleration rate in a vulnerable coastal wetland. Ecology and Evolution 7(24):10890-10903

Wu W, Biber P, Mishra DR, Ghosh S (2020) Sea-level rise thresholds for stability of salt marshes in a riverine versus a marine dominated estuary. Science of the Total Environment 718:137181

Zuur A, Ieno EN, Walker N, Saveliev AA, Smith GM (2009) Mixed effects models and extensions in ecology with R. Springer Science and Business Media, Berlin, Germany

\section{Statements and Declarations}

\section{Funding}

This work was funded in part by an award from the Office for Coastal Management, National Ocean Service, National Oceanic and Atmospheric Administration (award number NA21NOS4200046) and the Mississippi Tidelands Trust Program administered by the Mississippi Department of Marine Resources. 
559 The authors have no relevant financial or non-financial interests to disclose.

560

561 Author contributions

562 Study conception and design were performed by Jonathan L. Pitchford, Kimberly Cressman, Julia A. Cherry, Brook

563 T. Russell, and William V. Underwood. Material preparation, data collection and analysis were performed by

564 Jonathan L. Pitchford, Kimberly Cressman, Brook T. Russell, Jay McIlwain, and Michael J. Archer. The first draft

565 of the manuscript was written by Jonathan L. Pitchford, and all authors commented on previous versions of the

566 manuscript. All authors read and approved the final manuscript.

567

568

Data availability

569 The elevation and accretion datasets analyzed during the current study are available from National Oceanic and

570 Atmospheric Administration's Centralized Data Management Office at https://cdmo.baruch.sc.edu/get/landing.cfm.

571 This data and other generated datasets (e.g., water level rise data) can be provided by the corresponding author on

572 reasonable request. 